\title{
Klasifikasi Atribut Pelayanan Mobile Banking dengan Kano Model Berdasarkan Dimensi E-Servqual
}

Imam Safi'i

Jurusan Teknik Industri, Fakultas Teknik, Universitas Kadiri, Jalan Selomangleng No 1, Kediri, 64115, Indonesia

\section{ARTICLE INFORMATION}

Article history:

Received: August 27, 2018

Revised: December 18, 2018

Accepted: December 22, 2018

\section{Kata Kunci:}

E-Servqual

Kano Model

Kualitas Layanan

Mobile Banking

Keywords:

E-Servqual

Kano Model

Mobile Banking

Service Quality

${ }^{*}$ Corresponding Author

Imam Safi'i

imam@unik-kediri.ac.id

\begin{abstract}
A B S T R A K
Penelitian ini bertujuan untuk mengetahui klasifikasi atribut layanan mobile banking yang meningkatkan kepuasan pelanggan berdasarkan dimensi $\mathrm{E}$ Servqual menggunakan metode model Kano. Klasifikasi dibutuhkan agar pihak perbankan mampu melakukan perbaikan dan inovasi pada kinerja kualitas layanan mobile bankingnya. Dari hasil pengolahan data menggunakan model Kano diketahui atribut layanan yang perlu diperbaiki kinerjanya adalah fasilitas m-banking yang memiliki fitur layanan menarik uang tunai melalui ATM. Ini akan berdampak besar bagi kepuasan pelanggan karena atribut tersebut memiliki nilai koefisien kepuasan paling tinggi 0,67 pada klasifikasi one dimensional. Selanjutnya atribut layanan yang perlu dilakukan peningkatan dan inovasi adalah m-banking memiliki layanan pengaktifan ulang aplikasi dengan cepat dengan nilai koofisien kepuasan sebesar 0,61 pada klasifikasi attractive.
\end{abstract}

\section{A B S T R A C T}

This study aims to determine the classification of mobile banking services that improve customer satisfaction based on the dimensions of E-Servqual using the Kano Model method. The classification is needed so that the banks were able to make improvements and innovations in the performance of the quality of their mobile banking services. From the results of data processing using Kano, it is known that the service attributes that need to be improved are the $\mathrm{m}$-banking facility, which features a cash withdrawal service via ATM. This will have a major impact on customer satisfaction because these attributes have the highest satisfaction coefficient value of 0.67 in one-dimensional classification. Furthermore, service attributes that need to be improved and innovated are $\mathrm{m}$-banking has a fast application reactivation service with a satisfaction coefficient of 0.61 in the attractive classification.

\section{PENDAHULUAN}

Pertumbuhan jumlah ponsel pintar dan kemajuan teknologi komunikasi merupakan tren yang berkembang saat ini. Linfen [1] mengemukakan bahwa dengan perkembangan tren layanan mobile banking, semakin banyak layanan keuangan baru akan diberikan kepada pelanggan di masa depan. Survei dari MEF [2] menyatakan pada tahun $2014,80 \%$ responden di Indonesia menyatakan sudah menggunakan sarana mobile banking yang mengalami kenaikan dibandingkan tahun 2013 sebesar 58\%. Selain itu dampak dari penggunaan mobile banking ini membuat keuntungan tersendiri dari pihak perbankan. Pembayaran melalui perangkat, transaksi menggunakan Internet dari ponsel, akan mengurangi biaya layanan keuangan sebesar 80-90 persen [3]. Melihat fenomena tersebut pihak lembaga perbankan terus melakukan upaya untuk membuat nasabahnya menggunakan layanan mobile banking agar jumlah pengguna semakin meningkat. Namun disisi lain pihak perbankan 
juga perlu memperhatikan mengenai kepuasan pengguna mobile banking agar pelanggan tetap terus menggunakan dan memungkinkan terciptanya Word of Mouth (WOM). Pelanggan merasa puas jika apa yang diterima (nilai perceived) sama atau lebih banyak dari layanan yang diharapkan (nilai expectation) [4]. Tetapi jika kepuasan tidak dirasakan oleh pelanggan, maka yang terjadi adalah bentuk ketidakpercayaan pelanggan kepada pihak perbankan. Maka dari itu kualitas layanan mobile banking perlu diperhatikan kembali oleh pihak perbankan.

Kualitas layanan mobile banking yang diberikan sangat berpengaruh terhadap kepuasan pelanggan di Indonesia, seperti penelitian yang dilakukan oleh Wardhana [5] bahwa pengaruh kualitas layanan mobile banking terhadap kepuasan nasabah sebesar $59,29 \%$ dan sisanya sebesar $40,71 \%$ dipengaruhi oleh variabel lain. Dimensi kualitas layanan yang dipakai dalam penelitian tersebut meliputi Speed, Security, Accuracy, dan Trust [6] dalam mengungkap kualitas layanan mobile banking. Sejalan dengan penelitian tersebut, Febrianta and Indrawati [7] juga melakukan penelitian mengenai pengaruh kualitas layanan mobile banking terhadap kepuasan nasabah Bank BCA di Kota Bandung dengan memakai dimensi Reliability, Responsiveness, Assurance and Privacy, Convenience, Efficiency, dan Easiness to Operate yang mengadopsi dari dimensi dengan nama metode e-Servqual yaitu model untuk mengevaluasi kualitas jasa elektronik [8]. Dari kedua hasil penelitian tersebut sangat jelas jika tingkat kualitas layanan akan mempengaruhi kepuasan pelanggan dalam menggunakan mobile banking. Tetapi pihak perbankan juga perlu mengukur sejauh mana kualitas layanan mobile banking yang diberikan kepada pelanggan mampu memuaskan pelanggan, sehingga diharapkan adanya perbaikan (improvement) dan kepuasan pelanggan akan lebih meningkat. Dimensi kualitas layanan elektronik seperti efisiensi, interaktivitas, keamanan, informasi, kemudahan penggunaan dan konten adalah faktor kunci untuk mempengaruhi kepuasan pelanggan dalam layanan perbankan elektronik [9]. Akan tetapi $E$ Servqual tidak didesain sebagai tool untuk inovasi sehingga memerlukan tool tambahan seperti model Kano untuk menjawab keterbatasan-keterbatasan tersebut [10].

Kano [11] mengemukakan sebuah model yang membantu peneliti dalam membedakan antara tiga jenis layanan/produk yang mempengaruhi kepuasan pelanggan, yaitu must be requirement, One-dimensional requirements, dan Attractive requirements. Model Kano juga bisa memberikan perbedaan atribut dari layanan mobile banking sejauh mana atribut itu mampu memberikan pelayanan kepada pelanggan [12]. Penggabungan model Kano dan E-Servqual dapat menjawab keterbatasan-keterbatasan tersebut. Model Kano dapat membantu organisasi mengkategorikan atribut-atribut pengukuran kepuasan pelanggan berdasarkan hubungan antara kinerja dengan kepuasan pelanggan yang dihasilkan. Integrasi E-Servqual dan Model Kano mengasumsikan bahwa hubungan antara kinerja dengan kepuasan pelanggan tidak selalu linier. Mengacu pada definisi kategori Kano, maka pada integrasi ini atribut weak dengan kategori must-be dan onedimensional merupakan atribut yang harus diperbaiki (improve) sedangkan atribut dengan kategori attractive merupakan atribut yang bersifat inovatif [10].

Ada pun research questions yang akan dijawab dalam penelitian ini adalah bagaimana klasifikasi kepuasan pelanggan atas fasilitas dan layanan mobile banking yang diukur dengan metode Kano berdasarkan dimensi e-Service quality. Penelitian ini bertujuan untuk mengetahui atribut layanan mobile banking yang memberikan kepuasan pada pelanggan yang diwujudkan dalam klasifikasi kategori Kano. Diharapkan penelitian ini mampu memberikan informasi kepada pihak lembaga perbankan agar mampu memenuhi keinginan pelanggan sehingga kualitas layanan dapat ditingkatkan

\section{METODE PENELITIAN}

Penelitian ini dimulai dengan studi literatur untuk mengetahui dasar dari penelitian, kemudian melakukan observasi di lapangan guna mengetahui kondisi dari obyek yang diteliti, sehingga dapat mengetahui permasalahan yang 
akan dibahas dan dijadikan tujuan pada penelitian ini. Batasan masalah serta asumsi ditentukan agar penelitian ini tidak keluar dari tujuan penelitian yang dilakukan [13]. Batasan penelitian ini adalah mengklasifikasikan atribut pelayanan mobile banking sebagai dasar keputusan perbaikan di masa mendatang. Pengumpulan data diawali dengan membuat kuesioner berdasarkan atribut dari dimensi EServqual dengan mengkombinasikan antara dimensi dari Parasuraman, Zeithaml, \& Malhotra [8] dan Lovelock \& Gummesson [6] secara functional dan disfunctional. Kemudian menyebarkan kuisioner tersebut kepada pelanggan yang menggunakan layanan mobile banking di kota Kediri sebagai responden. Dalam penelitian ini jumlah sampel minimum menggunakan formula Lemeshow [14] untuk populasi tidak diketahui

$n=\frac{S^{2} \times A(1-A)}{b^{2}}$

Keterangan :

$\begin{array}{ll}n & : \text { Jumlah sampel } \\ \mathrm{S} & : \text { Tingkat kepercayaan } 95 \%=1,96 \\ A & : \text { maksimal estimasi }=0,5 \\ b & : \text { alpha }(0,10) \text { atau sampling error }=10 \%\end{array}$

Berdasarkan rumus di tersebut maka $n$ yang didapatkan adalah 96,04 atau dibulatkan menjadi 96 responden. Kemudian dari hasil kuisioner dilakukan uji validitas dan uji realibilitas untuk mengukur keandalan instrumen serta konsistensi dari pengambilan data dengan menggunakan bantuan software SPSS 13 for Windows. Setelah semua atribut dinyatakan valid dan reliabel, selanjutnya melakukan analisis Kano Model dengan tahapan sebagai berikut:

1. Mengevaluasi model Kano pada atribut yang terdapat dalam dimensi E-Servqual.

2. Menentukan kategori model Kano pada tiap atribut dengan menggunakan Blaut's Formula [15] yaitu :

- Jika (one dimensional + attractive + mustbe) $>$ (indifferent + reserve + questionable) maka grade dipilih dari yang paling maksimum(one dimensional, attractive, must be)

- Jika (one dimensional + attractive + mustbe) $<$ (indifferent + reserve + questionable) maka grade dipilih dari yang paling maksimum dari (indifferent, reserve, questionable)

- Jika jumlah (one dimensional + attractive + must-be) $=$ (indifferent + reserve + questionable) maka grade dipilih yang paling maksimum diantara kategori model Kano yaitu (one dimensional, attractive, must be, indifferent, reserve, questionable)

3. Menghitung customer satisfaction coefficient (CSC) dengan menilai if better than (IBT) yaitu jika hasil mendekati 1 , maka kehadiran karakteristik produk/jasa mempunyai pengaruh yang semakin besar terhadap kepuasan konsumen.

$\mathrm{IBT}=\frac{A+O}{A+O+M+I}$

Menilai if worse than (IWT) yaitu pengaruh ketidakhadiran suatu karakteristik produk terhadap ketidakpuasan konsumen semakin besar jika mendekati nilai -1 dengan rumus :

$\mathrm{IWT}=\frac{M+O}{A+O+M+I}$

4. Terakhir, menentukan klasifikasi posisi atribut dimensi E-Servqual pada model Kano seperti gambar 1. di bawah ini.

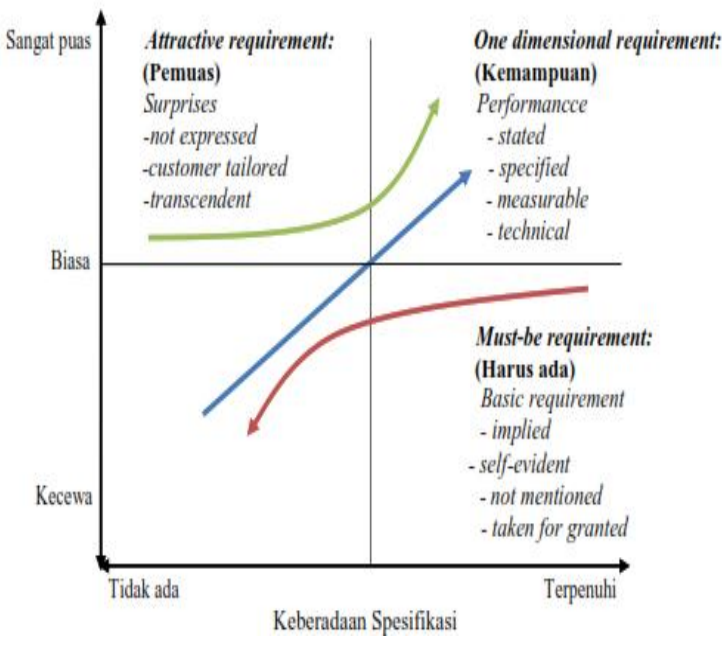

Gambar 1. Kano Model [16]

\section{HASIL DAN PEMBAHASAN}

\section{Karakteristik Responden}

Hasil pengumpulan dan pengolahan data 
mendapatkan karakteristik responden seperti tabel 1.

Tabel 1. Profil Responden

\begin{tabular}{lc}
\hline \multicolumn{1}{c}{ Karakteristik } & Jumlah \\
\hline Jenis Kelamin & \\
Laki-laki & $44,2 \%$ \\
Perempuan & $55,8 \%$ \\
Pendidikan & \\
SMP & $5,3 \%$ \\
SMA & $51,3 \%$ \\
S1 & $41,6 \%$ \\
S2 & $0,9 \%$ \\
S3 & $0,9 \%$ \\
Usia & \\
17 - 25 Tahun & \\
26 - 35 Tahun & $77,9 \%$ \\
36 - 59 Tahun & $13,3 \%$ \\
Jenis Pekerjaan & $8,8 \%$ \\
Pelajar/Mahasiswa & \\
Pegawai Swasta & $65,2 \%$ \\
Wiraswasta & $13,4 \%$ \\
& $13,4 \%$
\end{tabular}

Lain-lain

$8 \%$

\section{Atribut E-Servqual Mobile Banking}

Adapun instrumen yang dibuat berdasarkan variabel atribut E-Servqual pelayanan mobile banking seperti dimensi fulfillment, responsiveness, compensation, efficiency, system availability, privacy, dan contact (tabel 2). Dari hasil uji validitas 24 atribut variabel dimensi E-Servqual Mobile Banking diperoleh hasil valid karena semua item $r_{\text {Hitung }}$ lebih besar dari $r_{\text {Tabel }}$ yaitu nilai $r_{\text {hitung }}$ lebih besar dari 0,168 . Uji reliabilitas mendapatkan nilai tinggi, yaitu sebesar 0,962 >0,60. Hal ini menunjukkan hasil reliabilitas yang baik. berdasarkan hasil uji validitas dan reliabilitas tersebut maka penelitian ini dapat dilanjutkan ke tahapan berikutnya yaitu analisa atribut dimensi menggunakan metode KANO.

Tabel 2. Atribut Dimensi E-Servqual Mobile Banking

\begin{tabular}{|c|c|c|}
\hline Dimensi & Kode & Atribut \\
\hline Dimensi Fulfillment & $\begin{array}{l}\text { F1 } \\
\text { F2 } \\
\text { F3 } \\
\text { F4 } \\
\text { F5 }\end{array}$ & $\begin{array}{l}\text { m-banking memiliki tampilan menarik dan mudah dipahami. } \\
\text { m-banking memiliki prosedur layanan yang mudah. } \\
\text { m-banking memiliki informasi gangguan sistem yang diumumkan } \\
\text { segera. } \\
\text { m-banking memiliki image dan kredibilitas yang baik. } \\
\text { m-banking memiliki bukti transaksi yang mudah didapatkan. }\end{array}$ \\
\hline Dimensi Responsiveness & $\begin{array}{l}\mathrm{R} 1 \\
\mathrm{R} 2\end{array}$ & $\begin{array}{l}\text { m-banking memiliki layanan mutasi yang mutakhir. } \\
\text { Konsumen dapat menggunakan m-banking dengan mudah. }\end{array}$ \\
\hline Dimensi Compensation & $\begin{array}{l}\mathrm{C} 1 \\
\mathrm{C} 2 \\
\mathrm{C} 3\end{array}$ & $\begin{array}{l}\text { layanan m-banking memiliki prosedur transaksi yang dapat } \\
\text { mengurangi kesalahan input informasi. } \\
\text { layanan transaksi memberikan notifikasi status transaksi dengan } \\
\text { cepat. } \\
\text { m-banking memiliki informasi adanya tawaran produk yang } \\
\text { dimiliki. }\end{array}$ \\
\hline Dimensi Efficiency & $\begin{array}{l}\text { E1 } \\
\text { E2 } \\
\text { E4 } \\
\text { E5 } \\
\text { E6 }\end{array}$ & $\begin{array}{l}\text { m-banking memiliki layanan pengaktifan ulang aplikasi dengan } \\
\text { cepat. } \\
\text { m-banking memiliki verifikasi transaksi yang diberikan dengan } \\
\text { cara praktis. } \\
\text { m-banking memiliki layanan melakukan verifikasi identitas pemilik } \\
\text { rekening antar bank dengan mudah. } \\
\text { m-banking memiliki fitur pembayaran yang lengkap (kartu kredit, } \\
\text { Listrik, BPJS, Pajak, dll.) } \\
\text { m-banking memiliki fitur pembelian yang lengkap (Top Up, } \\
\text { Voucher Telepon, Beli paket data, dll). } \\
\text { m-banking memiliki fitur investasi didalam aplikasi. } \\
\text { m-banking memiliki fitur layanan menarik uang tunai melalui ATM. }\end{array}$ \\
\hline $\begin{array}{l}\text { Dimensi } \\
\text { Availability }\end{array}$ & $\begin{array}{l}\text { SA1 } \\
\text { SA2 }\end{array}$ & $\begin{array}{l}\text { m-banking memiliki tingkat enskripsi data yang tinggi. } \\
\text { m-banking memiliki sistem yang dapat bekerja dengan baik } \\
\text { selama } 24 \text { jam. }\end{array}$ \\
\hline Dimensi Privacy & $\begin{array}{l}\text { P1 } \\
\text { P2 } \\
\text { P3 }\end{array}$ & $\begin{array}{l}\text { m-banking memiliki jaminan data transaksi selalu aman. } \\
\text { m-banking memiliki id login sebelum menggunakan transaksi. } \\
\text { m-banking memiliki informasi jika ada gangguan penyusup dari } \\
\text { pihak lain. }\end{array}$ \\
\hline Dimensi Contact & $\begin{array}{l}\text { CT1 } \\
\text { CT2 }\end{array}$ & $\begin{array}{l}\text { m-banking memiliki fitur layanan chat atau pesan. } \\
\text { m-banking memiliki fitur layanan telepon untuk berbicara dengan }\end{array}$ \\
\hline
\end{tabular}




\section{Analisis Model Kano}

Dengan mengevaluasi dan mengkategorikan atribut dimensi E-Servqual Mobile Banking ke dalam model Kano berdasarkan nilai skala likert yang diperoleh dari kuisioner secara functional dan disfunctional maka didapatkan hasil seperti pada tabel 3. Setelah mengkategorikan kedalam Kano dilakukan perhitungan customer satisfaction coefficient (CSC) untuk mengetahui pengaruh kehadiran maupun ketidakhadiran atribut pelayanan mobile banking terhadap kepuasan pelanggan. Dari data CSC terlihat nilai IBT tertinggi sebesar 0,67 adalah pada dimensi Efficiency yaitu atribut E7 -banking memiliki fitur layanan menarik uang tunai melalui ATM.

Tabel 3. Evaluasi dan Pengkategorian Model Kano Pelayanan Mobile Banking

\begin{tabular}{|c|c|c|c|c|c|c|c|c|c|c|c|}
\hline \multirow{2}{*}{ No } & \multirow{2}{*}{$\begin{array}{l}\text { Kode } \\
\text { Atribut }\end{array}$} & \multicolumn{6}{|c|}{ Kategori Kano Model } & \multirow{2}{*}{ Total } & \multirow{2}{*}{ Kategori } & \multicolumn{2}{|c|}{ CSC } \\
\hline & & A & $M$ & $\mathrm{O}$ & $\mathrm{R}$ & $Q$ & I & & & IBT & IWT \\
\hline 1 & $\mathrm{~F} 1$ & 16 & 30 & 36 & 0 & 2 & 13 & 97 & $\mathrm{O}$ & 0,55 & $-0,69$ \\
\hline 2 & $\mathrm{~F} 2$ & 13 & 44 & 27 & 0 & 5 & 8 & 97 & M & 0,43 & $-0,77$ \\
\hline 3 & F3 & 9 & 39 & 27 & 2 & 7 & 13 & 97 & M & 0,41 & $-0,75$ \\
\hline 4 & $\mathrm{~F} 4$ & 9 & 31 & 30 & 4 & 2 & 21 & 97 & M & 0,43 & $-0,67$ \\
\hline 5 & F5 & 11 & 38 & 33 & 4 & 4 & 7 & 97 & M & 0,49 & $-0,80$ \\
\hline 6 & R1 & 17 & 34 & 30 & 2 & 2 & 12 & 97 & M & 0,51 & $-0,69$ \\
\hline 7 & $\mathrm{R} 2$ & 16 & 33 & 25 & 2 & 5 & 16 & 97 & M & 0,46 & $-0,64$ \\
\hline 8 & $\mathrm{C} 1$ & 15 & 26 & 36 & 3 & 7 & 10 & 97 & 0 & 0,59 & $-0,71$ \\
\hline 9 & $\mathrm{C} 2$ & 13 & 31 & 38 & 2 & 2 & 11 & 97 & 0 & 0,55 & $-0,74$ \\
\hline 10 & C3 & 13 & 14 & 13 & 5 & 11 & 41 & 97 & I & 0,32 & $-0,33$ \\
\hline 11 & E1 & 19 & 21 & 36 & 3 & 4 & 14 & 97 & 0 & 0,61 & $-0,63$ \\
\hline 12 & E2 & 16 & 33 & 35 & 0 & 1 & 12 & 97 & 0 & 0,53 & $-0,71$ \\
\hline 13 & E3 & 10 & 28 & 41 & 0 & 3 & 15 & 97 & 0 & 0,54 & $-0,73$ \\
\hline 14 & E4 & 32 & 12 & 30 & 2 & 1 & 20 & 97 & $A$ & 0,66 & $-0,45$ \\
\hline 15 & E5 & 26 & 17 & 29 & 1 & 5 & 19 & 97 & 0 & 0,60 & $-0,51$ \\
\hline 16 & E6 & 29 & 11 & 22 & 2 & 4 & 29 & 97 & $A$ & 0,56 & $-0,36$ \\
\hline 17 & E7 & 32 & 12 & 28 & 2 & 5 & 18 & 97 & $A$ & 0,67 & $-0,44$ \\
\hline 18 & SA1 & 17 & 26 & 27 & 1 & 2 & 24 & 97 & 0 & 0,47 & $-0,56$ \\
\hline 19 & SA2 & 14 & 31 & 33 & 1 & 2 & 16 & 97 & 0 & 0,50 & $-0,68$ \\
\hline 20 & P1 & 16 & 36 & 34 & 0 & 3 & 8 & 97 & $M$ & 0,53 & $-0,74$ \\
\hline 21 & P2 & 11 & 38 & 33 & 0 & 2 & 13 & 97 & $M$ & 0,46 & $-0,75$ \\
\hline 22 & P3 & 10 & 22 & 31 & 2 & 8 & 24 & 97 & 0 & 0,47 & $-0,61$ \\
\hline 23 & CT1 & 33 & 8 & 29 & 1 & 2 & 24 & 97 & $A$ & 0,66 & $-0,39$ \\
\hline 24 & СT2 & 34 & 11 & 27 & 1 & 1 & 23 & 97 & $A$ & 0,64 & $-0,40$ \\
\hline
\end{tabular}




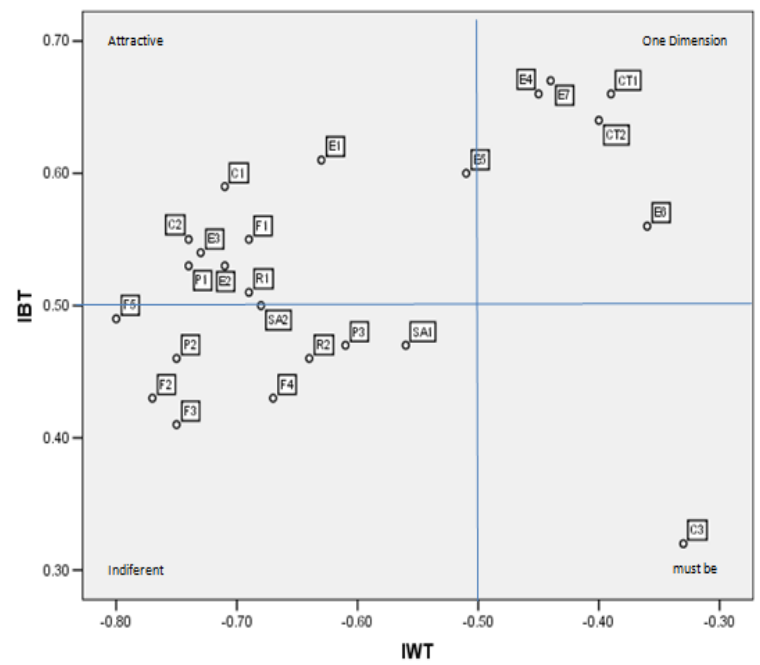

Gambar 2. Grafik Model Kano Pelayanan Mobile Banking

Sedangkan nilai IWT tertinggi sebesar $-0,77$ adalah pada dimensi Fulfillment yaitu atribut F2 $\mathrm{m}$-banking memiliki prosedur layanan yang mudah, artinya jika atribut ini tidak ada maka akan berpengaruh besar terhadap ketidakpuasan pelanggan. Penentuan klasifikasi posisi atribut dimensi E-Servqual pada Kano Model terlihat pada gambar 2. Bahwa atribut yang masuk klasifikasi must-be adalah C3 yaitu m-banking memiliki informasi adanya tawaran produk yang dimiliki artinya adanya layanan tersebut tidak akan meningkatkan kepuasan pelanggan. Sedangkan yang masuk klasifikasi one dimensional yang artinya jika adanya layanan tersebut maka akan meningkatkan kepuasan pelanggan, jika kinerja layanan tersebut menurun maka akan terjadi ketidakpuasan pelanggan, diantaranya adalah atribut (E4, E6, E7, CT1, dan CT2) yaitu:

1. m-banking memiliki fitur pembayaran yang lengkap (kartu kredit, Listrik, BPJS, Pajak, dll).

2. m-banking memiliki fitur investasi di dalam aplikasi.

3. m-banking memiliki fitur layanan menarik uang tunai melalui ATM.

4. m-banking memiliki fitur layanan chat atau pesan.

5. m-banking memiliki fitur layanan telepon untuk berbicara dengan Customer Service.

Pada kuadran one dimensional nilai IBT tertinggi adalah pada layanan m-banking memiliki fitur layanan menarik uang tunai melalui ATM yaitu sebesar 0,67 yang berarti atribut layanan tersebut dianggap penting karena dapat meningkatkan fitur layanan mobile banking yang menjadi kepuasan pelanggan.

Klasifikasi attractive, berarti bahwa adanya kinerja layanan tersebut akan meningkatkan nilai kepuasan pelanggan sangat tinggi, sebaliknya jika kinerja layanan tersebut menurun maka tidak akan menyebabkan penurunan nilai kepuasan pelanggan. Atribut yang masuk dalam attractive adalah (F1, C1, C2, E1, E2, E3, E5, P1, R1, dan SA2) yaitu :

1. m-banking memiliki tampilan menarik dan mudah dipahami.

2. layanan m-banking memiliki prosedur transaksi yang dapat mengurangi kesalahan input informasi.

3. layanan transaksi memberikan notifikasi status transaksi dengan cepat.

4. m-banking memiliki layanan pengaktifan ulang aplikasi dengan cepat.

5. m-banking memiliki verifikasi transaksi yang diberikan dengan cara praktis.

6. m-banking memiliki layanan melakukan verifikasi identitas pemilik rekening antar bank dengan mudah.

7. m-banking memiliki fitur pembelian yang lengkap (Top Up, Voucher Telepon, Beli paket data, dII).

8. m-banking memiliki jaminan data transaksi selalu aman.

9. m-banking memiliki layanan mutasi yang mutakhir.

10. $\mathrm{m}$-banking memiliki sistem yang dapat bekerja dengan baik selama 24 jam.

Dari ke 10 atribut yang masuk pada kuadran attractive yang mempunyai nilai IBT paling tinggi yaitu 0,61 ,berarti m-banking yang memiliki layanan pengaktifan ulang aplikasi dengan cepat akan memberi nilai kepuasan lebih dibanding atribut lainnya yang masuk kuadran attractive. Di sini perusahan perbankan perlu meningkatkan layanan tersebut.Saat pelanggan mengganti smartphone maka pelanggan akan diminta untuk mengaktifasi ulang mobile banking-nya, umumnya pelanggan harus melewati proses panjang dan memakan waktu yang lama. 
Tentunya jika ini terjadi maka bisa berdampak pada loyalitas penggunaan mobile banking.

Klasifikasi yang masuk pada indifferent adalah atribut (F2, F3, F4, P2, P3, R2, dan SA1) yaitu :

1. m-banking memiliki prosedur layanan yang mudah.

2. m-banking memiliki informasi gangguan sistem yang diumumkan segera.

3. m-banking memiliki image dan kredibilitas yang baik.

4. m-banking memiliki id login sebelum menggunakan transaksi.

5. m-banking memiliki informasi jika ada gangguan penyusup dari pihak lain.

6. Konsumen dapat menggunakan m-banking dengan mudah.

7. m-banking memiliki tingkat enskripsi data yang tinggi.

Ketujuh atribut di atas yang masuk pada kuadran indifferent tidak perlu difokuskan, karena tidak berpengaruh terhadap tingkat kepuasan pelanggan.

\section{KESIMPULAN}

Kepuasan pelanggan atas fasilitas dan layanan mobile banking menggunakan metode Kano Model berdasarkan dimensi E-Servqual diketahui Atribut layanan mobile banking yang memberikan pengaruh besar pada kepuasan pelanggan yaitu, memiliki fitur pembayaran yang lengkap (kartu kredit, Listrik, BPJS, Pajak, dII) dan mbanking memiliki fitur layanan chat atau pesan. Sedangkan layanan yang perlu diperbaiki adalah fasilitas $\mathrm{m}$-banking yang memiliki fitur layanan menarik uang tunai melalui ATM. Ini akan berdampak besar bagi kepuasan pelanggan karena atribut tersebut memiliki nilai koefisien kepuasan paling tinggi pada klasifikasi one dimensional. Atribut layanan $m$-banking memiliki layanan pengaktifan ulang aplikasi dengan cepat merupakan atribut dengan nilai koofisien kepuasan paling tinggi pada klasifikasi attractive yang artinya perusahaan harus meningkatkan kinerja layanan tersebut agar kepuasan pelanggan terus meningkat dengan memberikan proses dan waktu pengaktifan ulang yang lebih efektif dan efisien.

\section{DAFTAR PUSTAKA}

[1] C. Lingfen, D. Woods, K. Curran, and J. Doherty, "Mobile development environments for electronic finance," Int. J. Electron. Financ., vol. 4, no. 2, pp. 99 119, 2010.

[2] MEF, "Country Report: Indonesia Part Of The Mef Global Consumer Survey Series," Center for a New American Security Washington, DC, 2015.

[3] Tempo, "Pengguna Mobile Banking di Indonesia Masih Rendah," Bisnis Tempo, 2016.

[4] M. M. Ulkhaq and M. P. B. Barus, "Analisis Kepuasan Pelanggan dengan Menggunakan SERVQUAL: Studi Kasus Layanan IndiHome PT. Telekomunikasi Indonesia, Tbk, Regional 1 Sumatera," J. Sist. dan Manaj. Ind., vol. 1, no. 2, pp. 6167, 2017.

[5] A. Wardhana, "Pengaruh Kualitas Layanan Mobile Banking (M-Banking) Terhadap Kepuasan Nasabah di Indonesia [Effect of Mobile Banking (MBanking) Service Quality on Customer Satisfaction in Indonesia]," DeReMa (Development Res. Manag. J. Manaj., vol. 10, no. 2, pp. 273-284, 2015.

[6] C. Lovelock and E. Gummesson, "Whither services marketing? In search of a new paradigm and fresh perspectives," $J$. Serv. Res., vol. 7, no. 1, pp. 20-41, 2004.

[7] A. Febrianta and I. Indrawati, "Pengaruh Kualitas Layanan Mobile Banking Terhadap Kepuasan Nasabah Bank Bca Di Kota Bandung," eProceedings Manag., vol. 3, no. 3, 2016.

[8] A. Parasuraman, V. A. Zeithaml, and A. Malhotra, "ES-QUAL: A multiple-item scale for assessing electronic service quality," J. Serv. Res., vol. 7, no. 3, pp. 213-233, 2005.

[9] S. Firdous and R. Faroogi, "Impact of Internet Banking Service Quality on Customer Satisfaction," J. Internet Bank. Commer., vol. 22, no. 1, pp. 1-17, 2017.

[10] M. R. R. F and Y. Rohayati, "Analisis Kebutuhan Layanan Media Komunikasi Facebook Amanda Brownies Dengan Metode E-Service Quality dan Model Kano," Telkom University, 2014.

[11] N. Kano, "Attractive quality and must-be quality," Hinshitsu (Quality, J. Japanese Soc. Qual. Control., vol. 14, pp. 39-48, 1984.

[12] A. A. Aliyu, S. M. Lame, and M. Gafar, "Application of Kano's Model Approach in Mobile Banking and Customer Service," 
J. Appl. Sci. Res., vol. 9, no. 8, pp. 45274534, 2013.

[13] I. Safi'i and F. Handoko, "Kualitas Pelayanan Di Tinjau Dari Prestasi Akademik Mahasiswa Studi Kasus Pada Universitas Kadiri," J. Teknol. Dan Manaj. Ind., vol. 1, no. 2, pp. 22-27, 2017.

[14] P. S. Levy and S. Lemeshow, Sampling of populations: methods and applications. John Wiley \& Sons, 2013.

[15] D. Walden, "Kano Introduction," Cent. Qual. Manag. J., vol. 2, no. 4, pp. 3-7, 1993.

[16] C. Berger, "Kano's methods for understanding customer-defined quality," Cent. Qual. Manag. J., vol. 2, no. 4, pp. 3-36, 1993. 